\title{
Male Attendance at Title X Family Planning Clinics - United States, 2003-2014
}

\author{
Ghenet Besera, MPH${ }^{1}$; Susan Moskosky, MS²; Karen Pazol, $\mathrm{PhD}^{1}$; Christina Fowler, $\mathrm{PhD}^{3}$; Lee Warner, $\mathrm{PhD}^{1}$; David M. Johnson, MPH${ }^{2}$;
} Wanda D. Barfield, MD ${ }^{1}$

Although both men and women have reproductive health care needs, family planning providers traditionally focus services toward women $(1,2)$. Challenges in providing family planning services to men, including preconception health, infertility, contraceptive, and sexually transmitted disease (STD) care $(3,4)$, include their infrequent use of preventive health services, a perceived lack of need for these services $(1,5)$, and the lack of provider guidance regarding men's reproductive health care needs (4). Since 1970, the National Title X Family Planning Program has provided cost-effective and confidential family planning and related preventive health services with priority for services to low-income women and men. To examine men's use of services at Title X service sites, CDC and the U.S. Department of Health and Human Services' Office of Population Affairs (OPA) analyzed data from the 2003-2014 Family Planning Annual Reports (FPAR), annual data that are required of all Title X-funded agencies. During 2003-2014, 3.8 million males visited Title X service sites in the United States and the percentage of family planning users who were male nearly doubled from $4.5 \%$ (221,425 males) in 2003 to $8.8 \%$ (362,531 males) in 2014. In 2014, the percentage of family planning users who were male varied widely by state, ranging from $\leq 1 \%$ in Mississippi, Tennessee, and Alabama to $27.2 \%$ in the District of Columbia (DC). Title X service sites are increasingly providing services for males. Health care settings might want to adopt the framework employed by Title X clinics to better provide family planning and related preventative services to men (3).

To describe male client attendance at service sites funded under the National Title X Family Planning Program, CDC and OPA analyzed data from the 2003-2014 FPAR.* FPAR contains data from all entities that receive Title $\mathrm{X}$ grants to support the delivery of family planning and related preventive health services. In 2014, about four million clients were served through approximately 4,100 Title X service sites. Data were included from Title X service sites in the 50 states and DC and used to describe 1) trends in the percentage of family planning users who were male; 2) state-level variation in the percentage of family planning users who were male; 3 ) demographic characteristics of males who were family planning users; 4) percentage of males who adopted or continued use

\footnotetext{
*http://www.hhs.gov/opa/title-x-family-planning/research-and-data/ fp-annual-reports.
}

of a contraceptive method and method type; and 5) receipt of testing for chlamydia, gonorrhea, syphilis, and human immunodeficiency virus (HIV) among males. A family planning user was defined as a person who had at least one family planning encounter at a Title X service site in a calendar year, where an encounter consists of a documented, face-to-face contact with a family planning provider for the purpose of delivering services to clients who want to avoid unintended pregnancies or achieve intended pregnancies. For the purposes of inclusion in FPAR, written documentation of the services provided during the family planning encounter in the client record is required.

During 2003-2014, a total of 3.8 million males visited Title X service sites, and the percentage of family planning users who were male nearly doubled from $4.5 \%$ in 2003 to $8.8 \%$ in 2014 (Figure 1). The percentage of family planning users who were male increased each year during 2003-2014, with the exception of 2010-2011, when no change was observed (Figure 1). Among males aged 20-29 years, an increase occurred every year during 2003-2014, and among males aged $\geq 30$ years, an increase occurred every year except 2011 . In contrast, the percentage of users who were male and aged $<20$ years peaked in 2009 and 2010 at $1.8 \%$ and subsequently decreased (Figure 1). There was also a $63.7 \%$ increase in the overall number of male clients visiting Title X service sites from 221,425 in 2003 to 362,531 in 2014.

In $2014,34.6 \%$ of male family planning users were white, $27.6 \%$ were Hispanic, and $24.2 \%$ were black. Approximately half of male users $(49.0 \%)$ were aged $20-29$ years, with lower percentages aged 30-39 years (20.4\%) and 15-19 years (14.4\%) (Table). By state, there was wide variation in the percentage of total family planning users who were male, from lows in Mississippi $(0.7 \%)$, Tennessee $(0.7 \%)$, and Alabama $(1.0 \%)$ to highs in Rhode Island (16.1\%), Delaware (19.1\%), and DC (27.2\%) (Figure 2).

The majority (87.5\%) of male users adopted or continued use of a contraceptive method at the conclusion of their last family planning encounter in 2014, with the male condom being the most common (71.9\%). Two thirds of males (66.6\%) were tested for chlamydia. Receipt of chlamydia testing was highest among males aged 20-24 years (76.9\%) and lowest among males aged $<15$ years (15.5\%) (Table). In 2014, for every 10 male family planning users overall, Title $\mathrm{X}$ service sites also performed 7.5 gonorrhea tests, 3.3 syphilis tests, and 
FIGURE 1. Trends in the percentage of family planning users who were male, Title X service sites — United States, 2003-2014

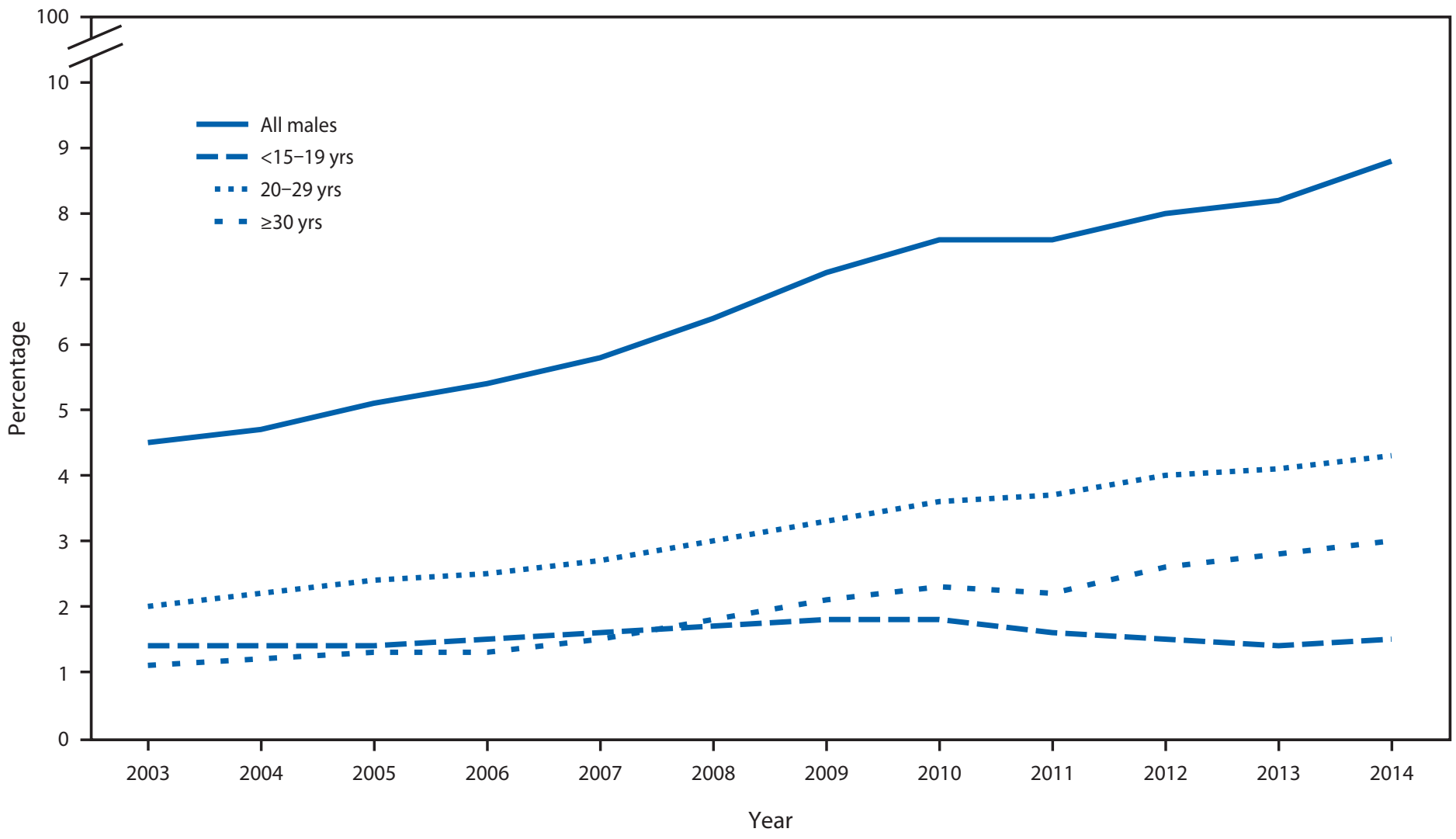

5.7 confidential HIV tests. By state, for every 10 male family planning users, the number of gonorrhea tests performed ranged from 0.7 (New Mexico) to 10.7 (Delaware); the number of syphilis tests performed ranged from 0.02 (New Mexico) to 9.5 (Alabama); and the number of HIV tests performed ranged from 0.02 (New Mexico) to 9.3 (Alabama).

\section{Discussion}

Although women continue to represent $>90 \%$ of Title X family planning clients, the percentage of family planning users who are men is increasing. During 2003-2014, the percent of family planning users who were men nearly doubled, with the most consistent increases occurring among men aged 20-29 and $\geq 30$ years. During the past 15 years, OPA has aimed to increase the number of men who use Title $\mathrm{X}$ services by funding projects and training to improve outreach and male-centered appropriate service delivery $(6)$.

In 2014, CDC and OPA published Providing Quality Family Planning Services: Recommendations of CDC and the U.S. Office of Population Affairs, which describes services that should be offered in a family planning visit, and guidance for providing those services to both men and women (3). Recommended services for men include education and counseling on a range of issues related to preventing or achieving pregnancy, including, but not limited to, preconception health, infertility, contraception, and STD and HIV care (3). Preconception health, infertility, and STD and HIV services are included as family planning services because they improve the overall health of women and men and can influence their ability to conceive or have a healthy birth outcome (3). Title X sites also connect men with broader primary care services, through referral or direct provision of services.

These recommendations can be used by providers to offer family planning services to men, thereby improving their access to sexual and reproductive health care $(3,4)$. Family planning services are embedded within a broader framework of services, such that providers assess the client's need for related preventive services even when the primary reason for their visit relates to preventing or achieving pregnancy (3). The recommendations are also designed to optimize opportunities to provide men with reproductive health services by converting a standalone visit (e.g., a complaint related to an STD) to a more comprehensive family planning visit that also addresses issues related to unintended pregnancy prevention (e.g., sexual risk, reproductive health planning, and contraception) $(3,4)$. This approach is especially important for serving the family planning needs of men, who might not otherwise receive these services (4). 
TABLE. Distribution of male family planning users by race/ethnicity, age group, chlamydia testing, and primary contraceptive method, Title X service sites — United States, 2014

\begin{tabular}{|c|c|}
\hline Demographic characteristic & (\%) $\mathrm{N}=362,531$ \\
\hline \multicolumn{2}{|l|}{ Race/Ethnicity } \\
\hline Black* & 24.2 \\
\hline Hispanic $^{\dagger}$ & 27.6 \\
\hline White* & 34.6 \\
\hline Other ${ }^{\S}$ & 13.7 \\
\hline \multicolumn{2}{|l|}{ Age group (yrs) } \\
\hline$<15$ & 2.5 \\
\hline $15-19$ & 14.4 \\
\hline $20-24$ & 27.0 \\
\hline $25-29$ & 22.0 \\
\hline $30-34$ & 13.0 \\
\hline $35-39$ & 7.4 \\
\hline$\geq 40$ & 13.8 \\
\hline \multicolumn{2}{|l|}{ Services provided } \\
\hline \multicolumn{2}{|l|}{ Tested for chlamydia } \\
\hline Total & 66.6 \\
\hline \multicolumn{2}{|l|}{ Age group (yrs) } \\
\hline$<15$ & 15.5 \\
\hline $15-19$ & 60.5 \\
\hline $20-24$ & 76.9 \\
\hline$>24$ & 65.4 \\
\hline \multicolumn{2}{|l|}{ Primary contraceptive method } \\
\hline Vasectomy & 0.8 \\
\hline Male condom & 71.9 \\
\hline Rely on female method & 6.0 \\
\hline Abstinence & 5.8 \\
\hline Other" & 3.0 \\
\hline Total & 87.5 \\
\hline Method unknown or not reported & 5.7 \\
\hline No method** & 6.8 \\
\hline
\end{tabular}

* Non-Hispanic or non-Latino.

† Persons identified as Hispanic might be of any race.

$\S$ Non-Hispanic or non-Latino: American Indian or Alaska Native, Asian, Native Hawaiian or other Pacific Islander, unknown, and multiple race; unknown/ not reported ethnicity.

" Other methods include fertility awareness-based methods, withdrawal, or any other method not included in the Family Planning Annual Report reporting table.

** No primary method, either because their partners were pregnant or seeking pregnancy or for other reasons.

The findings that provision of male condoms and testing for STDs were common among male users of family planning services and that most male family planning clients were Hispanic or black are similar to those reported in other studies $(7,8)$. Meeting men's needs related to contraception and STD testing is essential, considering the role men can play in preventing unintended pregnancy and given the high rates of STDs among men, especially low-income and minority men $(2,4,9)$. Addressing these needs as an opportunity to promote "dual protection" (i.e., preventing both unintended pregnancy and STD) benefits both men and their partners.

The findings in this report are subject to at least two limitations. First, because only summary information on a limited number of client characteristics is required to be collected from
FIGURE 2. Percentage of family planning users who were male, Title X service sites — United States, 2014

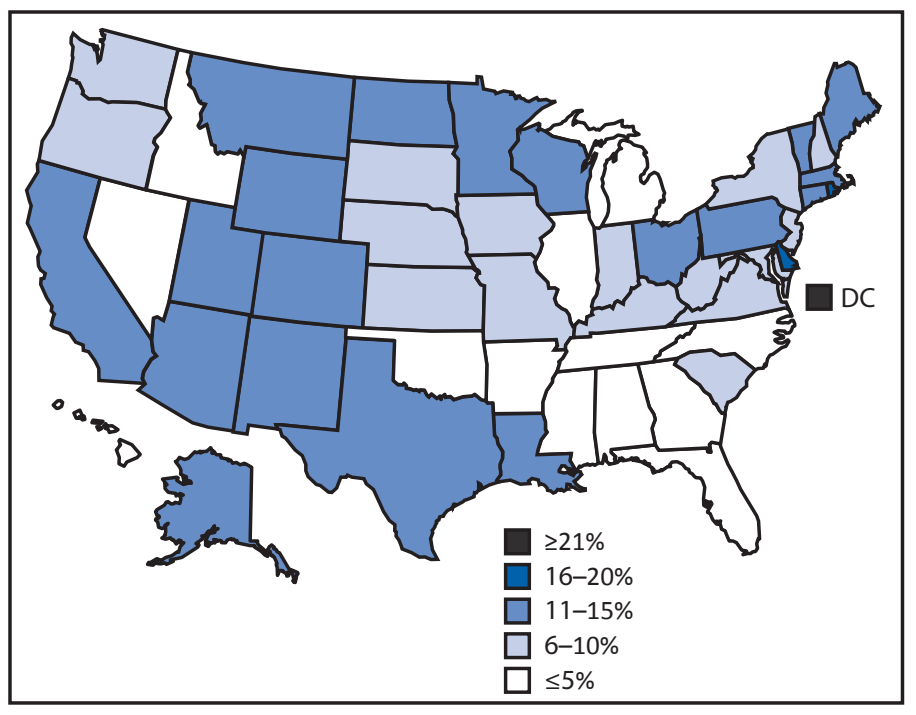

\section{Summary}

What is already known about this topic?

Although both men and women have reproductive health care needs, reproductive health services traditionally focus on women. Since 1970, the Title X program has provided family planning and related preventive health services with priority for services for low-income women and men. Most clients are women, but the Title $\mathrm{X}$ program also promotes use of clinics by men through delivery of male-focused health services.

What is added by this report?

Title X service sites have increasingly provided services to male clients. During 2003-2014, 3.8 million males visited Title X service sites in the United States and the percentage of all family planning users who were male nearly doubled from $4.5 \%$ $(221,425)$ in 2003 to $8.8 \%(362,531)$ in 2014 . In 2014 , the percentage of family planning users who were male ranged widely by state from $\leq 1 \%$ in Mississippi, Tennessee, and Alabama to $27.2 \%$ in the District of Columbia.

What are the implications for public health practice?

Health care settings might want to adopt the framework employed by Title $X$ clinics to better provide family planning and related preventive health services to men.

Title X grantees for the FPAR, certain types of client characteristics (e.g., sexual orientation and education) and services provided (e.g., preconception care and infertility) could not be assessed. Second, there are possible errors in reporting from service sites. However, using administrative data routinely reported by clinics eliminates the possibility of biases related to relying on client self-report, especially as it relates to sexual and reproductive health topics. 
Meeting the sexual and reproductive health needs of men and women is important for improving their overall health. Although men's use of family planning services remains low compared with that of women, an increasing number of men seek family planning and related preventive health services at Title X service sites. To meet the needs of the growing number of male clients, these services should be offered using a client-centered, male-focused approach in health care settings (e.g., Federally Qualified Health Centers and urology and family practice health care settings) that provide sexual and reproductive services to men.

${ }^{1}$ National Center for Chronic Disease Prevention and Health Promotion, CDC; ${ }^{2}$ Office of Population Affairs, US Department of Health and Human Services, Rockville, Maryland; ${ }^{3}$ RTI International, Research Triangle Park, North Carolina.

Corresponding author: Ghenet Besera, GBesera@cdc.gov, 770-488-6326.

\section{References}

1. Kalmuss D, Tatum C. Patterns of men's use of sexual and reproductive health services. Perspect Sex Reprod Health 2007;39:74-81. http://dx.doi. org/10.1363/3907407
2. Sonfield A. Looking at men's sexual and reproductive health needs. Guttmacher Rep Public Policy 2002;5:7-10.

3. Gavin L, Moskosky S, Carter M, et al. Providing quality family planning services: recommendations of CDC and the U.S. Office of Population Affairs. MMWR Recomm Rep 2014;63(No. RR-4).

4. Marcell AV, Gavin LE, Moskosky SB, McKenna R, Rompalo AM. Developing federal clinical care recommendations for men. Am J Prev Med 2015;49(Suppl 1):S14-22. http://dx.doi.org/10.1016/j.amepre.2015.03.006

5. Chabot MJ, Lewis C, de Bocanegra HT, Darney P. Correlates of receiving reproductive health care services among U.S. men aged 15 to 44 years. Am J Mens Health 2011;5:358-66. http://dx.doi. org/10.1177/1557988310395007

6. Office of Population Affairs. Male family planning services. Washington, DC: US Department of Health and Human Services, Office of Population Affairs; 2016. http://www.hhs.gov/opa/title-x-family-planning/ initiatives-and-resources/male-services/

7. Finer LB, Darroch JE, Frost JJ. Services for men at publicly funded family planning agencies, 1998-1999. Perspect Sex Reprod Health 2003;35:202-7.

8. Raine T, Marcell AV, Rocca CH, Harper CC. The other half of the equation: serving young men in a young women's reproductive health clinic. Perspect Sex Reprod Health 2003;35:208-14. http://dx.doi. org/10.1363/3520803

9. CDC. Sexually transmitted disease surveillance 2014. Atlanta, GA: US Department of Health and Human Services, CDC; 2015. http://www. cdc.gov/std/stats14/surv-2014-print.pdf 